\title{
Research on the Paths of Domestic Cars Go out of Low-End Situation-Take Lifan Cars for Example
}

\author{
Lei He \\ School of Economics, Shanghai University, Shanghai, China \\ 1542797209@qq.com
}

Keywords: Car industry chains; Modularization; Lifan cars; Low-end situation

\begin{abstract}
Car industry is of large economic scale, with long industry chains, having huge impact on national economy and social life. In recent years, production and sales of cars in our country have increased significantly, we have been large producer of cars already, but the the competitiveness of cars industry and enterprises is weak, at a disadvantage in the international car market. The thesis based on industry chain perspective to analysis china car industry, then discuss on how to improve its competitiveness through modularization. After theoretical analysis, use domestic Lifan cars as case study, and explore practical ways to help Lifan cars out of low-end situations.
\end{abstract}

\section{国产汽车走出中低端的路径一以力帆汽车为例}

\author{
何蕾 \\ 上海大学 经济学院, 中国 上海 200444 \\ 1542797209@qq.com
}

摘要: 汽车产业经济规模大, 产业链条长, 对国民经济发展和社会生活都有着巨大的影响。 近年来, 我国汽车产销量大幅提高, 已成为世界汽车生产大国, 但汽车产业和企业竞争能力 弱, 在国际汽车产业市场中处于劣势地位。本文基于产业链的视角, 在对我国汽车产业展开 分析, 探讨如何通过模块化提高汽车产业竞争力。在理论分析的基础上, 对国产力帆汽车从 产业链角度展开案例分析。并切实探索力帆汽车走出中低端的途径。

关键词：汽车产业链；模块化；力帆汽车；中低端

\section{1. 引言}

在国外, “产业链” 多被 “生产链”、“价值链”、“供应链” 等概念取代, 少有关于产业 链直接的论述, 但很多学者对价值链、供应链进行了研究。在价值链的研究中, Shank 和 Gowindarajan (1992) 认为价值链包括从最初的供应商到原材料到将最终产品送到用户手中 的全过程, 提出了内部价值链和外部价值链的概念。Rayport 和 Sviokla (1995) 提出了虚拟 价值链的概念, 强调了信息在虚拟价值链中的重要作用。Gereffi 和 Humpry (2005) 认为价值 链治理模式可分为科层制、领导型、关系型、模块型和市场, 并对其之间关系进行了研究。 在供应链的研究中, Billington (1995) 认为供应链是一个通过链中不同企业的制造、组装、 分销、零售等过程, 将原材料转换成产品, 再到最终用户的转移过程。Lin F. R (1998) 认为 供应链是包括供应商、制造商、销售商在内，涉及物流、资金流、信息流的企业网络系统。 Lambert (1997) 则认为供应链不应局限于单一企业中, 应将物流通路过程中所有成员视为一体, 并以生产、配送及分销等活动作为制定决策的层次。

在国内, 杨公朴、夏大慰 (2002) 认为产业链的实质是产业关联, 而产业关联的实质是各产 业间供给、投入与产出的关系。刘贵富 (2009) 探讨了产业链形成动因, 认为企业加盟产业链 的目的为实现价值最大化和经营风险最小化。赵红岩 (2008) 认为产业链的演进经历四种经济 阶段, 产业链在规模经济阶段和专业化分工阶段是纵向一体化的整合方式, 在模块化及网络 
化阶段呈现网状特征。

目前国内越来越多的学者开始具体对汽车产业链展开研究, 孙倩, 陈俊芳 (2005) 从价值链的 角度分析中国汽车产业现存的问题, 阐述了价值链反一体化的必要性, 并对其实施提出了相 关建议。寇小玲, 王溥 (2008) 从全球汽车产业链的组织和利润分布入手, 探讨了中国汽车产 业嵌入全球产业链的形式和对策。金友平 (2009) 在分析我国电动汽车产业链发展现状的基础 上, 提出了优化我国电动汽车产业链的建议。

\section{2. 汽车产业链分析}

\section{1. 一般意义上的纵向汽车产业链}

从一般意义上来说, 产业链可以分为横向的产业链和纵向一体化的产业链。传统意义上的产 业链指上中下游企业之间的纵向一体化关系, 一般意义上的汽车产业链可以表示如下图 1 。 从上中下游角度进行划分图 1 的产业链, 那么汽车产业链的上游是原材料供应、零件加工、 部件配套, 中游是整车装配, 下游是汽车的销售和售后服务。在汽车的生产过程是从生产单 个零件的到总成关键零部件, 再到装配整车, 这一过程是系统的工程。就汽车产业链中不同企 业的特征而言, 产品开发、市场营销、售后服务对整车企业而言极其重要, 而零部件企业核 心竞争力则主要在于工艺上的创新、在生产过程中对产品质量的保证、提供配套性强的零部 件。对于汽车产业链的一个核心问题是如何对价值链进行纵向关系的治理, 即如何基于特定 产业链纵向环节间组织关系或制度安排来实现上下游间的交易问题。

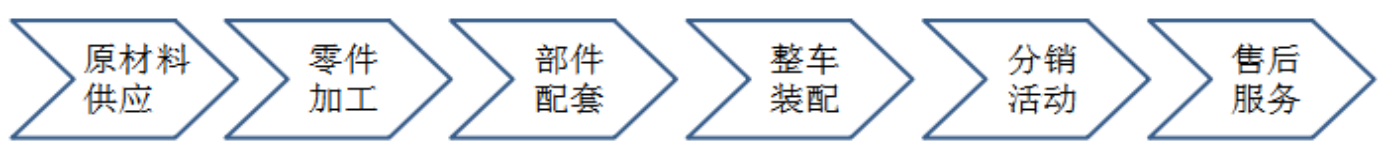

图 1 汽车产业链

2.2. 汽车产业价值链的利润分配

对汽车产业链不同环节间利润分配的研究有助于企业根据自身的市场地位制定有效的发展战 略。在对汽车产业价值链的分析中可以和 “微笑曲线” 相结合。“微笑曲线” 的概念最先是 根据 IT 行业全球价值链的变化趋势提出, 现已被加工修整为 “产业微笑曲线” 为各产业制 定长期发展策略提供方向指导。

“微笑曲线” 用图来表示制造工序流程中的附加价值, 在图 2 中可以看出其是根据附加价值 的高低来判断企业的竞争力。就汽车行业来说, 汽车产业链上游的产品研发创新、下游的营 销创新和售后服务已逐步成为汽车行业利润的主要来源, 原本附加值最高的整车组装已经变 成最没有价值的部分。因此, 在全球化的大背景下, 汽车行业只有不断创新进取, 向 “微笑 曲线” 两端逐步升级，才能争取竞争的主动，扩大附加值及利润空间。

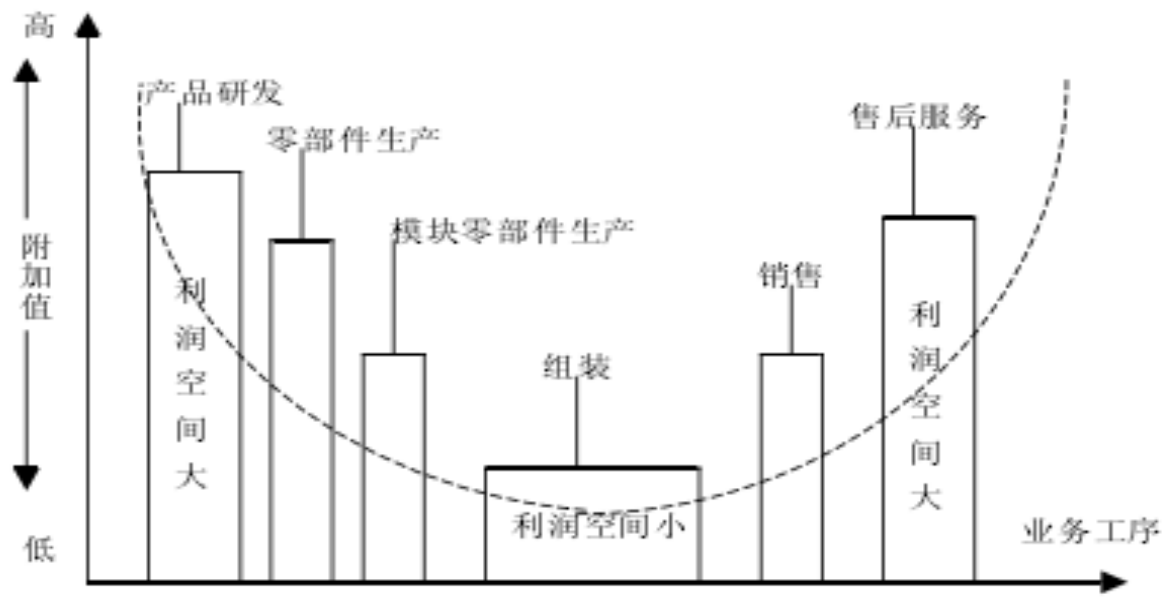




\section{图 2 “微笑曲线”示意图}

\section{3. 汽车产业全球价值链分析}

通过以上分析可以看出, 对于汽车产业来说, 价值链中的战略环节集中在研发, 关键零部件 及品牌销售等几个方面。从汽车产业的上下游关系角度看, 汽车价值链可看作涉及上游钢铁、 有色金属、橡胶、汽车修理、提供装备的机械、电子、电器等领域, 还延伸到销售市场、道 路交通及金融、保险等诸多方面的一条长链。

在传统大批量生产模式下，供应链相对简单，设计和生产都由汽车制造商负责的，且大部分 整车由制造商运送给销售商。随着全球化竞争的加剧, 汽车和汽车零部件技术越来越复杂, 推动了汽车制造商对内部组织结构进行重组。汽车大国纷纷将零部件从内部剥离出去, 在全 球范围内寻找制造商, 其自身将竞争力集中在车型设计、品牌、整车装配和市场销售与服务 方面，以使运作体系更有效率。

特别是 20 世纪 90 年代以来，随着生产和贸易全球化的不断深入，全球汽车产业价值创造体 系出现了前所未有的垂直分离和重构。一方面, 跨国汽车公司将竞争力重心由生产制造转移 到了汽车研发、销售与售后服务、汽车服务等高附加值环节; 另一方面, 包括中国在内的众 多发展中国家汽车产业由于接受了大量从发达国家转移出来的生产制造等价值环节, 获得了 千载难逢的发展机遇。

\section{3. 模块化视角下汽车产业链的整合}

\section{1. 网络状产业链的发展}

传统的产业链具有线性的结构，是在生产工艺流程划分的基础上产生的。而模块化的价值链 不再是工艺性的分工, 而是一种功能性的分工, 是模块化的产品生产。也就是说, 模块化的 价值链中, 复杂的产品中每一功能与其他功能间的联系不再是简单的线性联系, 而不断呈现 出网络状的联系, 协同演进的网络状关联越来越明显。具体线性产业链和网络状产业链的比 较见下表 1 。

需指出的是网络状产业链的创新是分散的, 在严格遵循系统设计规则的基础上, 每个独立模 块可自主创新, 这使得知识创新能够被整个产业链快速地吸收整合。具体来说, 网络状产业 链包括网络状产品链、网络状价值链、网络状知识链三个层面。

表 1 网络状产业链与传统产业链的主要区别

\begin{tabular}{|c|c|c|c|c|}
\hline 产业链摸式 & 生产方式 & 知识的信息透明度 & 创新方式 & 价值选择 \\
\hline 线性产业檤 & 传统 & 内隐在每个企业内部 & 集成创新 & 单一 \\
\hline 网络状产业链 & 模决化生产 & $\begin{array}{l}\text { 系统信息公开 } \\
\text { 模块信息内隐 }\end{array}$ & 分散创新 & 多样 \\
\hline
\end{tabular}

\section{2. 汽车在实际生产中模块化的操作方式}

汽车在实际生产组装时, 模块化的操作方式将体现在零部件层次的模块化和整车层次的模块 化这两个基本层次上。

3.2.1 零部件层次的模块化 
零部件层次的模块化主要体现在：零部件生产具有共享性和互换性的特征。通过模块间共享 和互换，同一个零部件子模块可以被用于不同品牌、不同厂商、甚至不同车型的系统模块生 产和组装中，而具有相同功能的子模块也可相互替代。这样一来，零部件层次上的子模块就 很容易在系统模块中执行分割、替代、扩展、排除、归纳、移植等 “模块化操作” ，临时性 改变了适应系统模块保证系统运行最佳效果得以实现。该种模块化使零部件企业获得更多的 订单和业务; 一些有实力的供应商将成为某一模块的专家，加速技术创新步伐。

3.2 .2 整车层次的模块化

零部件层次的模块化主要体现在: 汽车总装厂作为规则设计者和系统集成者, 通过构建结构 模块, 设计界面模块, 选择竞争模块, 集成最终模块实现降低成本、提高收益、增强创新的 目的。整车的模块化过程中, 总装厂只需设定标准化的制造规则, 并掌握发动机等核心部件 生产，其他部件完全可采用模块化的外包式、购进式组装。该种生产模式下，汽车可在不同 的场所进行局部装配，后再汇集起来进行集中装配。在同一个标准的主模块上工作得同时允 许在任何时间地点插入不同的分模块。这样实现了规模经济效益、范围经济效益、分工经济 效益、网络经济效益的统一, 最终客户的多样性需求得以满足。

\section{4. 对力帆汽车的案例分析}

4.1. 力帆汽车发展

力帆汽车的发展主要可以分为两个阶段, 分别是 2010 年 11 月 25 日力帆股份在上海证券交易 所成功上市，成为中国首家整体上市 A 股的民营乘用车企业前和后。

4. 1.1 力帆汽车上市之前的发展大事件

1992 年力帆汽车厂正式成立; 1994 年力帆在全国率先开发出四冲程 100 型发动机, 随后力帆 又相继开发出 90、100 型电启发动机； 2000 年 3 月 8 日力帆成为重庆第一家拥有进出口公司 的民营企业; 2006 年 1 月 19 日力帆推出了第一款自主品牌轿车一力帆 520；2010 年 3 月 31 日力帆携手中科院成立上海中科力帆电动汽车有限公司，新能源战略正式启动;

4. 1.2 力帆汽车上市之后的发展大事件

继上市以来， 2012 年 6 月 25 日，力帆股份斥资 4.77 亿元建设汽车、摩托车研发大楼及检测 中心研发中心; 2012 年 11 月 22 日，力帆自主研发的首款 A+级家用旗舰车型力帆 720 正式上 市并公布官方售价为 7.98 万元; 2013 年 5 月 24 日, 国务院副总理汪洋在视察了力帆汽车埃 塞俄比亚工厂期间，叮嘱力帆须坚持 “走出去” 的发展战略，打造成世界品牌; 2013 年 10 月 19 日，国家发改委对外公布的国家认定企业技术中心 2013 年评价结果中力帆技术中心排 名上升 92 位, 专利拥有量高居行业前茅, 居汽车行业第八位; 2014 年 10 月 31 日, 首款小 型 SUV 力帆 X50 全网上市, 这是国内首款通过 “欧洲标准” 的小型 SUV, 预示力帆汽车全球 化战略迈进新的台阶。

\section{2. 力帆汽车的产业链分析}

4.2. 1 产品研发

力帆一直致力于加强科研实力和提升技术水平, 成立了力帆汽车研究院, 并与英国里卡多、 美国麻省理工学院、中科院等多个研究机构建立了长期技术合作。截至 2013 年底, 公司全球 累计授权专利达 6900 多项, 位居汽车行业第二位, 这也为公司新车型的研发提供了有力的技 术保障。据力帆股份预计, 汽车新产品研发项目完成后, 可于 2017 年实现营业收入约 105 亿 元，净利润约 4 亿元。

在自主研发上，力帆 2014 年 7 月定增 17 亿投向汽车研发和金融项目，其中拟使用 8.2 亿元 用于新款中级轿车、小型城市 SUV、紧凑型城市 SUV、混合动力技术的研发。力帆集团总裁表 示力帆的研发投入非常大, 第一次 IP0 上市, 第一、二次定增主要都是用于研发, 2015 年定 向增发的 52 亿元，主要都是用于研发系统，一个是 “新能源+互联网”，另一个就是传统燃 油汽车的提升。从表 2, 2014 年研发费用占营业收入比重也可看出, 力帆研发费用占营业收 
入比率居于较高水平。

表 2 乘用车企业研发费用占营业收入比率排名（2014）

\begin{tabular}{|l|l|l|l|c|}
\hline 排序 & 证券代码 & 企业名称 & 研发费用（万元） & 占营业收入比率 \\
\hline 1 & 002594 & 比亚迪 & $287,248.00$ & $5.43 \%$ \\
\hline 2 & 601238 & 广汽集团 & $98,700.00$ & $5.24 \%$ \\
\hline 3 & 601777 & 力帆集团 & $51,574.97$ & $5.12 \%$ \\
\hline 4 & 000572 & 海马汽车 & $50,485.89$ & $4.93 \%$ \\
\hline 5 & 000625 & 长安汽车 & $162,000.00$ & $3.90 \%$ \\
\hline 6 & 000927 & 一汽夏利 & $21,915.00$ & $3.63 \%$ \\
\hline 7 & 600418 & 江淮汽车 & $121,943.29$ & $2.98 \%$ \\
\hline 9 & 601633 & 长城汽车 & $169,288.01$ & $2.20 \%$ \\
\hline 10 & 000800 & 一汽轿车 & $65,400.00$ & $0.94 \%$ \\
\hline
\end{tabular}

但从力帆汽车和大众汽车的研发投入对比来看, 大众汽车 2012 年共投入 95 亿欧元用于研发, 2013 年共投入 102 亿欧元， 2014 年共投入 115 亿欧元，不仅逐年增长，且投入力度高达力帆 汽车的数十倍, 研发对产出的贡献率也远大于力帆汽车。

4.2.2 力帆汽车销售情况

根据力帆汽车发布的 2014 年半年度报告, 公司实现营业收入 48.996 亿元, 比上年同期增长 $4.92 \%$, 净利润 2.38 亿元，比上年同期增长 $34.82 \%$ 。出口金额 32.31 亿元，出口金额保持重 庆市民营制造企业第一, 其中轿车（含 SUV）出口位列自主品牌出口第三名。乘用车实现销 售收入 32.25 亿元，同比增长 9.79\%，出口 23.26 亿元，同比增长 $49.07 \%$ 。

根据以下来自搜狐汽车网的图 3、图 4 可以看出力帆 X60 在力帆汽车乘用车的销售中占据领 导性的地位, 力帆 X60 现今是力帆旗下的顶梁柱。2015 年 1 月力帆 X60 的销量为 6352 辆, 虽然 2 月份下降至 4280 辆，但随后反弹至 5000-6000 辆的区间内，目前累计销量已达 32291 辆, 占到力帆整体销量的近 1/3。定位小型 SUV 级别的 X60 售价在 7-9 万元之间, 对普通消 费者而言比较易于接受, 但在该级别中, 长安 CS35、瑞风 S3 等对手竞争优势明显, 价格与 其接近，品质过硬，相比之下暴露出自身短板，销量远不及其他对手也是情理之中。

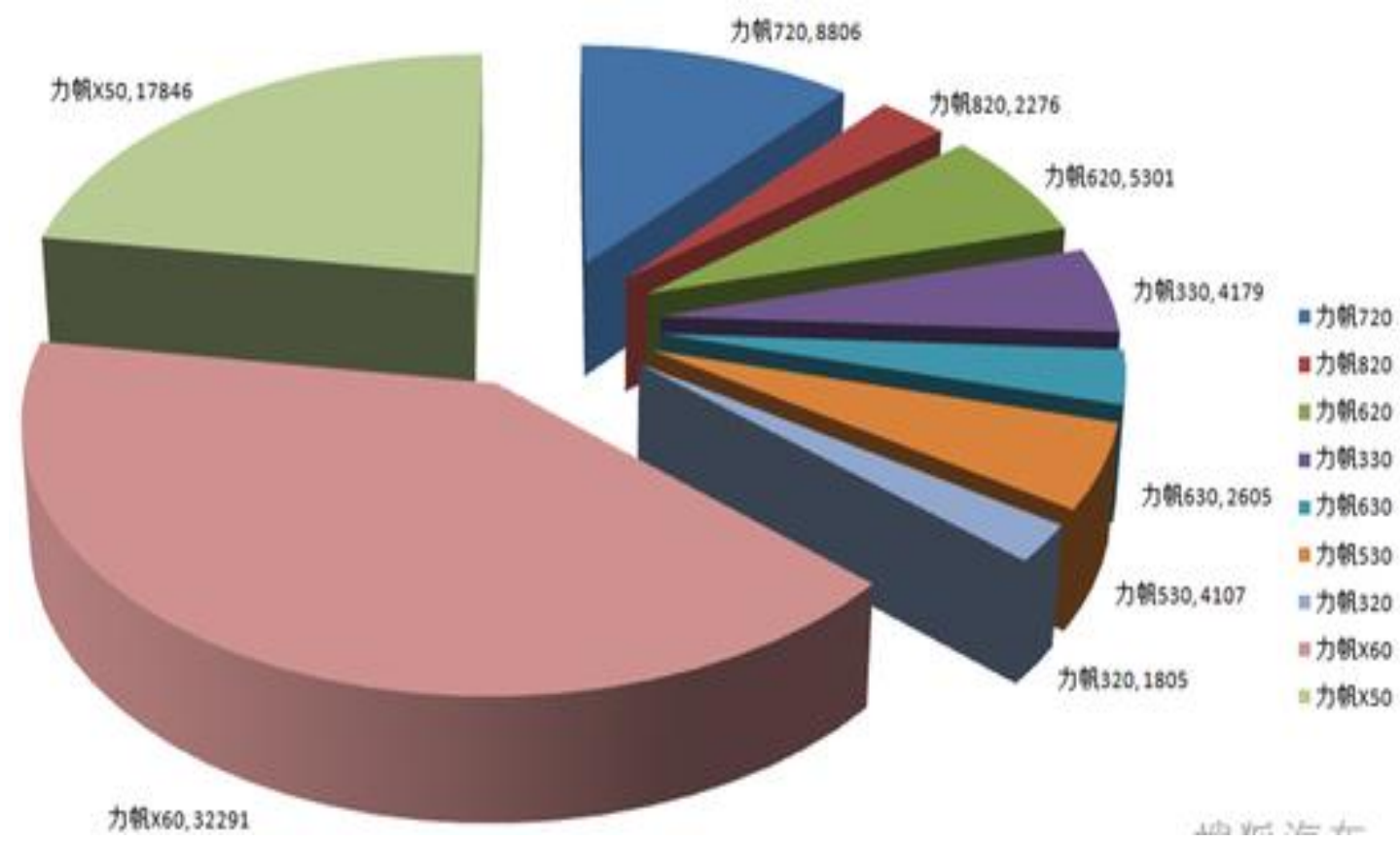


图 3 力帆乘用车 2015 年上半年销量构成（辆）

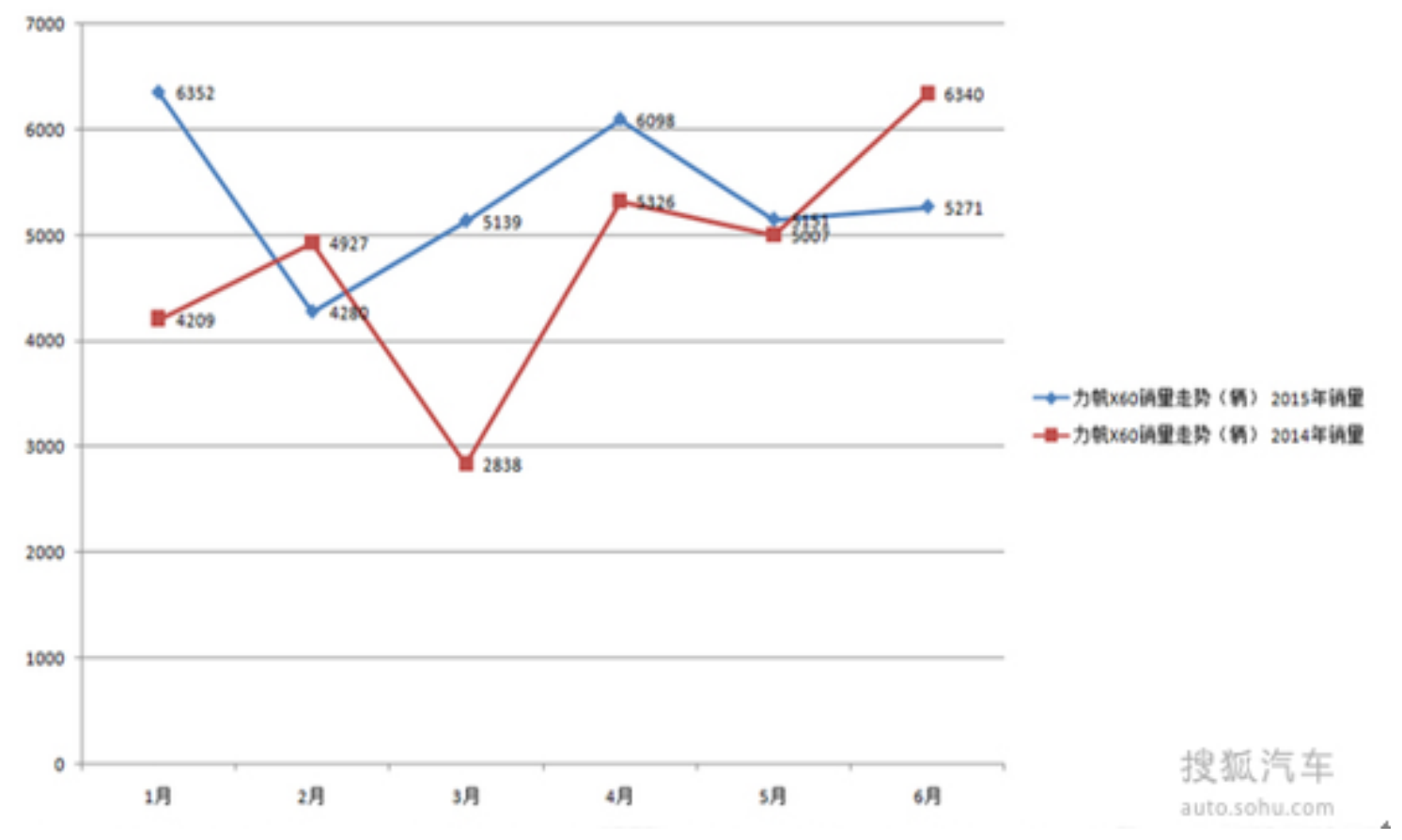

图 4 力帆 X60 2014-2015 上半年销量走势

\section{2 .3 力帆汽车的营销策略}

在汽车的营销策略上, 力帆汽车注重互动化营销。在互动营销中，互动的双方分别是消费者 和企业。抓住共同利益点, 找到巧妙的沟通时机和方法将双方紧密的结合起来是该营销方法核 心所在。互动营销尤其强调, 双方都采取一种共同的行为。通常意义上来说, 互动的形式很 容易被消费者接受, 且互动方式多种多样, 很容易出现良好的效果, 活动效果便于宣传。2011 年 7 月, 力帆首款 SUV 车型力帆 X60 开始了它的 “寻找最美的故乡” 之旅, 整个行程经过了 重庆、四川、甘肃、陕西、河南、山东、浙江等多个省市, 为力帆 X60 上市后的推广产生了 积极的影响, 事实证明, 力帆 X60 本次活动取得了良好的效果, 该活动也获得 2011 年度搜狐 金营销奖 “最佳互动效果奖”。

另外, 力帆汽车的营销还注重差异化营销, 差异化营销又叫差异性市场营销, 是指面对已经 细分的市场，企业选择两个或者两个以上的子市场作为市场目标，分别对每个子市场提供针 对性的产品和服务以及相应的销售措施。企业根据子市场的特点, 分别制定产品策略、价格 策略、渠道策略以及促销策略并予以实施。具体来说, 力帆汽车在产品开发方面, 不遗余力, 连续推出针对小众市场的多数车型。以 $320 \mathrm{CVT}$ 版本的推出为例, 随着国家家庭汽车保有量的 增长, 新手司机不断增加, 对于车辆的驾驶便利性也提出了更高的要求, 针对这一变化, 320VT 在坚持低油耗的同时加入了无级变速, 从而令操控更加简单便捷。可以说差异化的营销自始 至终贯穿于力帆汽车的方方面面，力帆汽车注重针对不同需求的市场研发不同车型。

\section{5. 结论}

提高国内汽车行业的竞争力离不开模块化的生产方式的大力运用。同时像 “微笑曲线” 的两 端升级, 大力发展产品研发、销售和售后服务等高附加值项目。但就目前来说, 结合我国汽 车制造业大国的国情, 国内汽车自主品牌有自己的优势, 对国内消费者的心理更有研究, 消 费者可以买到性价比更高的汽车, 自主品牌应该努力做到扬长避短。或许力帆汽车当下不必 一定去竞争高端, 鉴于并非所有消费者均一味追求高价位高端产品。自主品牌应该充分发挥 品质好, 性价比高这些自主品牌汽车的优势。力帆汽车如能将追求的目标由技术第一转变为 
品质第一，性价比第一将会有更大的盈利空间。加之因为中国有十几亿人口，中国国产品牌 的市场还是巨大的，无论什么品牌，生存的空间是一定有的。对于力帆汽车如何进一步提高 销售量，扩大市场份额，主要思考如下：就长期目标而言，力帆汽车在研发环节，应进一步 加大资金研发投入，注重核心技术的开发; 而在整车装配中，应更大注重整车装配中模块化 平台的构建；针对汽车售后而言，提高售后服务质量显得更加不可或缺; 在具体的汽车营销 策略上，进一步多元化有助于增大力帆汽车的市场份额占有率，提高企业的利润率。

\section{参考文献}

[1] Shank J, Gowindarajan V. Strategic Cost Management: the Value Chain Perspective[J].Journal of Management Accounting Research, (1992),No.4,pp.177-199.

[2] J.F. Rayport , J.J. Sviokla. Exploiting the Virtual Value Chain[J]. Harvard Business Review (1995), No 6, pp. 75-85.

[3] Gereffi G, Humphrey J, T.J. Sturgeon. The Governance of Global Value Chains[J]. Forthcoming in Review of International Political Economy, Vol. 12 (2005) No.1, pp.78-104.

[4] H.L. Lee, Billington C. The Evolution of Supply Chain Management Models and Practices at Hewlett Packard[J]. Interfaces, Vol. 25(1995) No.5, pp. 42-63.

[5] F.R. Lin, M.J. Shaw. Reengineering the Order Fulfillment Process in Supply Chain Networks[J].International Journal of Flexible Manufacturing Systems, Vol. 10 (1998) No.3, pp.197-229.

[6] M.C. Cooper, D.M. Lambert, J.D. Pagh. Supply Chain Management: More Than a New Name for Logistics[J]. The International Journal of Logistics Management, Vol.8 (1997) No. 8, pp.1-14.

[7] 杨公朴、夏大慰. 现代产业经济学 $[\mathrm{M}]$.上海: 上海财经大学出版社, 2002: 50-80.

[8] 刘贵富. 产业链形成机理的理论模型 $[J]$. 河南社会科学，2009，(1)：49-52.

[9] 赵红岩. 产业链整合的演进与中国企业的发展 $[J]$. 当代财经，2008，(9)：78-83.

[10] 孙倩, 陈俊芳. 中国汽车产业价值链存在的问题及解决方案 $[\mathrm{J}]$. 生产力研究, 2005, (6): 162-164.

[11] 寇小玲, 王溥. 中国汽车产业嵌入全球产业链对策的思考 $[\mathrm{J}]$. 经济纵横, 2008, (11): 53-56.

[12] 金友平. 我国电动汽车产业链的发展状况及优化路径[J]. 湘潮(下半月), 2009, (11): 69-70.

[13] 杨宇昕. 从产业价值链看中国汽车零部件企业发展战略[D].武汉科技大学,2004.

[14] 邓晓娜. 全球价值链下重庆汽车产业集群发展研究[D].重庆工商大学,2009.

[15] 沈慧芬. 基于模块化的中国汽车产业转型战略研究[D].浙江工商大学,2012.

[16] 刘袁娜. 力帆上半年实现销售收入 32.25 亿元 中国汽车报

[17] 汽车之家.力帆定增 17 亿投向汽车研发和金融项目 2014.8.18

[18] 张祖新,彭松. 扬帆致远 力帆汽车营销全解析[J]. 家用汽车,2013,01:96-103.

\section{References}

[1] Shank J, Gowindarajan V. Strategic Cost Management: the Value Chain Perspective [J]. Journal of Management Accounting Research, (1992), No.4, pp.177-199. 
[2] J.F. Rayport, J.J. Sviokla. Exploiting the Virtual Value Chain [J]. Harvard Business Review (1995), No 6, pp. 75-85.

[3] Gereffi G, Humphrey J, T.J. Sturgeon. The Governance of Global Value Chains [J]. Forthcoming in Review of International Political Economy, Vol. 12 (2005) No.1, pp.78-104.

[4] H.L. Lee, Billington C. The Evolution of Supply Chain Management Models and Practices at Hewlett Packard [J]. Interfaces, Vol. 25(1995) No.5, pp. 42-63.

[5] F.R. Lin, M.J. Shaw. Reengineering the Order Fulfillment Process in Supply Chain Networks [J]. International Journal of Flexible Manufacturing Systems, Vol. 10 (1998) No.3, pp.197-229.

[6] M.C. Cooper, D.M. Lambert, J.D. Pagh. Supply Chain Management: More Than a New Name for Logistics [J]. The International Journal of Logistics Management, Vol.8 (1997) No. 8, pp.1-14.

[7] Yang Gongpu, Xia Dawei:“ Modern Industrial Economics” [M].Shanghai University of Finance and Economics Press,(2002), p.50-80 (in Chinese)

[8] Liu Guifu:"Theoretical Models of The Chain Formation Mechanism"[J].Henan Social Sciences,(2009) ,No.1,p.49-52 (in Chinese)

[9] Zhao Hongyan: "Integration of Industry Chains and Development of Chinese Enterprises ’[J].Contemporary Finance \& Economics,(2008),No.9,p.78-83 (in Chinese)

[10] Sun Qian,Chen Junfang:"The Problems of China Automotive Industry Value Chain and Solutions to it '[J].Productivity Research,(2005), No.6,p162-164 (in Chinese)

[11]Kou Xiaoling, Wang Bo: “Thinking of Strategies to Help China's Auto Industry Embed To Global Industrial Chain” [J]. Economic Review,(2008), No.11,p53-56 (in Chinese)

[12]Jing Youping: "China's Electric Vehicle Industry Chain Development and Its Optimization Path Studies"[J].Xiang Chao,(2009), No.11,p69-70 (in Chinese)

[13] Yang Yuxin: "A View From Industry Value Chain to Development Strategy of Chinese Automotive Parts Enterprise"[D]. Wuhan University of Science and Technology (2004) (in Chinese)

[14]Dun Xiaona: "Research of Chongqing Auto Indusrrial Cluster Development Based On Global Value Chain"[D].Chongqing Technology and Business University (2009) (in Chinese)

[15] Shen Huifeng: "Chinese Auto Industry Transformation Strategy Research Based On the Modularization"[D]. Zhejiang Gongshang University(2012) (in Chinese)

[16]Information on http://www.cnautonews.com/cyc/pcv_sc/201409/t20140904_324076.htm

[17] Information on http://stock.hexun.com/2014-07-08/166432436.html

[18]Zhang Xinzu, Peng Song:“ Sailing of Lifan Cars: Full Analysis of Lifan Marketing Strategy” [J].Family Cars, (2013), No.01,p96-103 (in Chinese)

作者简介: 何蕾 (1993年-), 女, 安徽省合肥市, 主要研究方向: 产业经济, 邮箱: 1542797209@qq.com 